\title{
Shaping the Evolution of the Company Products Market by Applying Markov Chains Method
}

\author{
Gurãu Marian Andrei*
}

Department of Engineering and Technological Systems Management at the "Polytechnic" University, Bucharest, Romania.

${ }^{*}$ Corresponding Author: Email:andreigurau@yahoo.com

\begin{abstract}
This article present the Markov chains method, stages of implementation, the advantages and disadvantages of using it in the market analysis context of a company products. A Markov chain represents the stochastic process as such, its state being present, future conditions are independent of the past. In a Markov process, at every moment, the system can keep or change the status, according to some probability distributions. The case study presents the real situation of a furniture production company who wishes to identify the consumers number, their preferences at any time, their loyalty and how to shift them in the future. After conducting a market study on clients, data processing was performed using MARKOV process module of the WinQSB software, decizional analysis software. After the completion of such analysis and dragging over it findings, the company can develop a new strategy for the future, growth of investments or change some products, in order to attract a larger number of clients.
\end{abstract}

Keywords: Modeling, Markov chains, Market share, Markov processes, Win QSB software.

\section{Introduction}

Among the aspects that contribute to the increase of economic efficiency is included a justification strategy regarding sales policy for minimizing the negative influences generated by the main competitors. For this is recommended to realize a research of the position recorded on the market of products, which contribute most to the company turnover [1].

Markov chain method is a very good alternative, provided by economic-mathematical modeling, to study evolutions in the market products in relation with those of competitors. The advantage of this method is easily getting of some relevant information, which may contribute, to the improvement of marketing and strategic management to facilitate your activity through the development of strategies based on the product life cycle $[1,2]$.

Andrey Andreyevich Markov was a Russian mathematician who has put its mark on stochastic processes; his research has covered a large number of areas in mathematics, differential equations, theory of probabilities. The results of his work have great applicability and nowadays, being known by users as Markov chains. To be able to analyze a system using Markov chain, it must present the following characteristics [3].
To operate on a number of time intervals.In each of the time intervals, the system may be in a finite number of states.

The states in which is the system in a certain period are mutually exclusive (system find out during a period in one and only one of the possible conditions).switching system from one state to another in different periods can be described by crossing probabilities that remain constant.

The probability that the system to be in a certain state in a specific interval depends only on the system state in the previous period and the probability of crossing from one status to another; These applications are based on the idea, that the efficiency organization is influenced largely by its internal components, but at the same time, an important force that acts on its processes is competition. Starting from this assumption, it can see the importance of company position and its evolution in relation to its opponents, which carries the name of the position in market share [2].

\section{Markov Model}

Using Markov model can study the evolution of variables in the future by analyzing their present behavior in the form of processes that take place 
in succession. In other words present determine the future. This model is based on a system,

which in each phase is in a state, which belongs of a lot states (results) [4].

According the model, each result is associated with a probability $(p)$, which determines the transition from one state to another, transition from one current state 0 to another 1 is based on transition probabilities noted with $p_{i j}$. If $i=j$ it presents fidelity for initial state, and in the situation in which the system is located in the same state during a period then it remained in its original state $=i$. Crossing probabilities influence the long term behavior of the system as well as his behavior in the short term. The short-term behavior of the system depends on the state of the system during the current period and crossing probabilities.

In the theory of Markov chains is considered as the result of any transitions depend on the transition result, which precedes directly and only from it, transition which can be either a win or a loss $[2,3,5]$.

All crossing probabilities are grouped in the form of a transition matrix or crossing probabilities matrix, with the number of lines and columns equal to the number of possible states. It represents the connection between two consecutive phases, made according to the fidelity coefficient and reorientations. To solve the problem it is necessary to build an initial distribution vector consists of initial possibilities of the system, having a static character specific to a particular moment in its evolution.

Determining the products evolution on the market using Markov chains, require only knowledge of present state and transition probabilities. Two states of Markov process are known: recurrent state and transient state. The recurrent state is determined by the certitude that a process will return at a certain known state in a future moment. If there is a possibility that the process was no longer in that phase, then the state is known as transient. The main advantage of using Markov chain in comparison to the other methods is the rapidity and simplicity of calculations, as

The interpretation of table 2:The degree of client's fidelity towards products of a society is located at the intersection of the line and the column with the same name of the producer (red background). $70 \%$ from the customers who buy in this moment from Logy Bick, will buy its products also in the future, the rest of $30 \%$ will switching to competitors (10\% toward Mobexpert, $7 \%$ to Staer, $5 \%$ to Elvila, $4 \%$ to Domus Nuvo, 3\% to Hondor Still, $1 \%$ to Others). well as the facility of interpretation. So the current decisions will lead to the adoption of

strategies to change the prices, correct management of advertising or the granting of promotional features [6].

Although the use of Markov chain represents a satisfactory way to predict the choice of a particular brand by customers, the model has some limitations $[3,6]$.

Customers don't always buy products under the same intervals and don't always buy the same amount of products. This means that in future, two or more brands can be bought at the same time.

Customers always enter or dropping out of certain markets and therefore markets are never stable.

The transition probabilities, as a customer to pass from a brand $i$ to a brand $j$, are not constant for all buyers, these probabilities may change from buyer to buyer and from time to time.

These probabilities can change in accordance with the average of time between purchase situations.

The time between the different purchase situations can be a function of the last bought brand.

The other branches of the marketing environment like promotion, advertising, competition, etc. were not included in this model.

\section{Case Study-Logy Bick Furniture Company}

\section{Information about Company Products}

In order to be able to use Markov chains, the company Logy Bick Ltd realised a marketing study, which identify the number of consumers, their preferences at a time of furniture products and users of competing products [2].

The market study was realising in the period 01.01.2012-01.07.2012 by Ellipse Marketing Company.

Analysis of competition products furniture company Logy Bick Ltd, Constanta: the results of the market study (comparative analysis of furniture Logy Bick Ltd and the main competitors) are presented in tables 1 and 2 :

The market leader in this time, Mobexpert, will keep $85 \%$ of current clients because of quality products; others will switch due the price;

Staer will keep $59 \%$ of current clients, Elvila will keep 51\%, Domus Nuvo 68\%, Hondor Still $42 \%$, Others 23\%.

Reorientation of the competitors' customers to Logy Bick will do so: 4\% from Mobexpert customers, $11 \%$ from Staer customers, 10\% from 
Table 1: Analysis of furniture competing companies

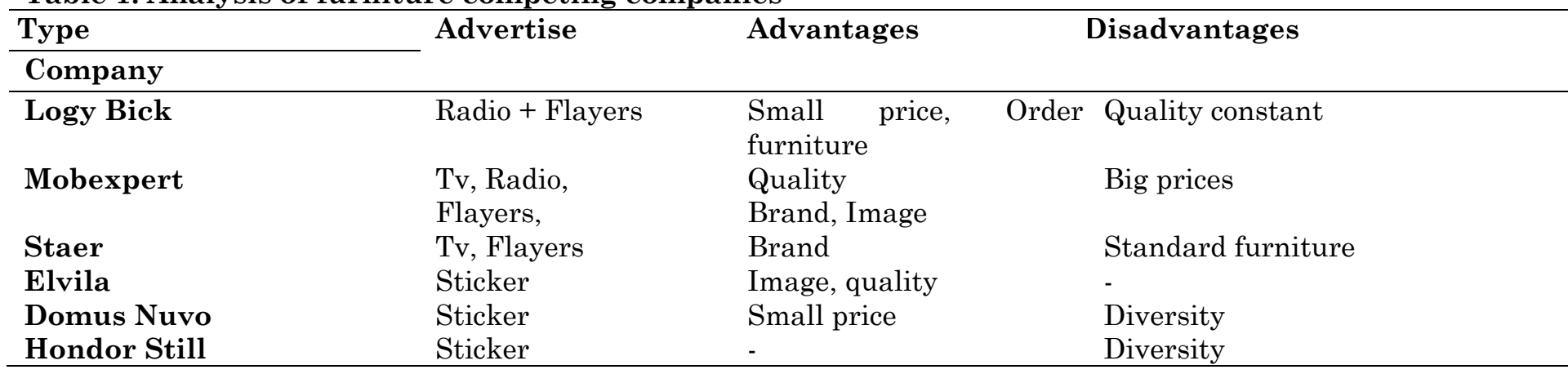

Table 2: Customers fidelity and reorientation

\begin{tabular}{|c|c|c|c|c|c|c|c|}
\hline \multirow{2}{*}{$\begin{array}{l}\text { Furniture } \\
\text { bought at the } \\
\text { present time }\end{array}$} & \multicolumn{7}{|c|}{ Reorientation (\%) } \\
\hline & Logy Bick & Mobexpert & Staer & Elvila & $\begin{array}{l}\text { Domus } \\
\text { Nuvo }\end{array}$ & $\begin{array}{l}\text { Hondor } \\
\text { Still }\end{array}$ & Others \\
\hline Logiy Bick & $70 \%$ & $10 \%$ & $7 \%$ & $5 \%$ & $4 \%$ & $3 \%$ & $1 \%$ \\
\hline Mobexpert & $4 \%$ & $85 \%$ & $2 \%$ & $4 \%$ & $2 \%$ & $1 \%$ & $2 \%$ \\
\hline Staer & $11 \%$ & $5 \%$ & $59 \%$ & $10 \%$ & $5 \%$ & $4 \%$ & $6 \%$ \\
\hline Elvila & $10 \%$ & $15 \%$ & $4 \%$ & $51 \%$ & $10 \%$ & $7 \%$ & $3 \%$ \\
\hline Domus Nuvo & $6 \%$ & $4 \%$ & $12 \%$ & $5 \%$ & $68 \%$ & $3 \%$ & $2 \%$ \\
\hline Hondor Still & $8 \%$ & $9 \%$ & $11 \%$ & $10 \%$ & $13 \%$ & $42 \%$ & $7 \%$ \\
\hline Others & $14 \%$ & $15 \%$ & $12 \%$ & $16 \%$ & $10 \%$ & $10 \%$ & $23 \%$ \\
\hline Market share & $17 \%$ & $33 \%$ & $14 \%$ & $10 \%$ & $16 \%$ & $7 \%$ & $3 \%$ \\
\hline
\end{tabular}

Elvila customers, 6\% from Domus Nuvo customers, $8 \%$ from Hondor Still customers and $14 \%$ from other producers' customers. This shift to the Logy Bick is due to the lower prices, good quality, the type of furniture sold, complete services offered, etc.

\section{Estimates of the Furniture Market Share}

The data processing from table 2 will be done with the WinQSB software, the Markov Process module [2].

WinQsb represents software with windows interface and with small limitations on the size of the problems to solve. It is very easy to import data in other programs and offer options to control the appearance of printed pages. In addition, it has implemented modules for almost all operational research problems: Decision Analysis, Dynamic Programming, Forecasting, Job Scheduling, Linear and Integer Programming, Markov Process, Network Modelling, Nonlinear Programming, PERT/CPM, Quadratic Programming, Quality Control Chart [7, 8]. WinQSB allow navigation between modules of the product, i.e. the selection of a particular type of problem.

As a result of the use of this module were obtained following data and results: In the dialog window that appears behind New option from File menu is specifying a title for the problem and the number of considered states.

MKP Problem Specification
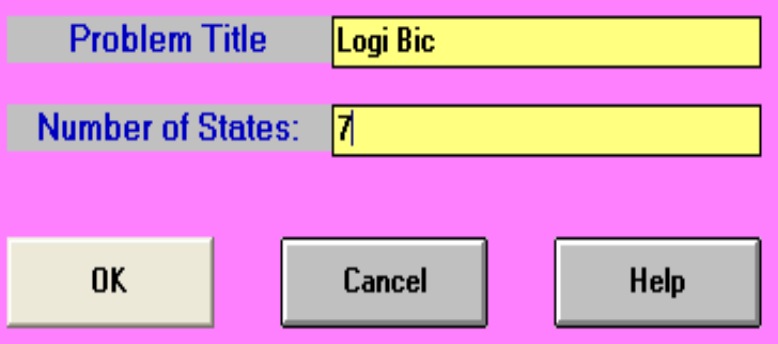

Fig.1: Problem specifications

According to the data from table 5 and according to the schedule presented in fig. 2 , it can observed that there will be a growing market share of Logy Bick from $17 \%$ to $17.7 \%$ in the first period, the rate will continue to grow until $18,65 \%$ threshold. The main producer on the market Mobexpert will have an increasing from $33 \%$ to $36,69 \%$.During the period considered, Logy Bick consolidates their second position on furniture market, most competitors suffering decreasing of the market share. 
Table 3: Initial data entry problem

\begin{tabular}{|c|r|r|r|r|r|r|r|}
\hline From \To & State1 & \multicolumn{1}{|c|}{ State2 } & State3 & State4 & State5 & State6 & \multicolumn{1}{c|}{ State7 } \\
\hline State1 & 0.7 & 0.1 & 0.07 & 0.05 & 0.04 & 0.03 & 0.01 \\
\hline State2 & 0.04 & 0.85 & 0.02 & 0.04 & 0.02 & 0.01 & 0.02 \\
\hline State3 & 0.11 & 0.05 & 0.59 & 0.1 & 0.05 & 0.04 & 0.06 \\
\hline State4 & 0.1 & 0.15 & 0.04 & 0.51 & 0.1 & 0.07 & 0.03 \\
\hline State5 & 0.06 & 0.04 & 0.12 & 0.05 & 0.68 & 0.03 & 0.02 \\
\hline State6 & 0.08 & 0.09 & 0.11 & 0.1 & 0.13 & 0.42 & 0.07 \\
\hline State7 & 0.14 & 0.15 & 0.12 & 0.16 & 0.1 & 0.1 & 0.23 \\
\hline Initial Prob. & 0.17 & 0.33 & 0.14 & 0.1 & 0.16 & 0.07 & 0.03 \\
\hline State Cost & & & & & & & \\
\hline
\end{tabular}

Table 4: Solutions - steady state

\begin{tabular}{|c|c|c|c|}
\hline $07-15-2012$ & State Mame & State Probability & Hecurrence Time \\
\hline 1 & State1 & 0.1853 & 5.3976 \\
\hline 2 & State2 & D.7709 & 2.EGEA \\
\hline $\mathbf{3}$ & State3 & 0.1216 & B.220B \\
\hline 4 & State 4 & 0.1085 & $9.218 \mathrm{~g}$ \\
\hline 5 & State5 & 0.1301 & 7, БВЯ日D \\
\hline$E$ & State6 & 口.प5口प & 20_DDझБ \\
\hline \multirow[t]{2}{*}{7} & State? & 口_DヨЭ7 & 29.7023 \\
\hline & Expected & CostrReturn = & $\mathbf{0}$ \\
\hline
\end{tabular}

Table 5: Solutions - time parametric analysis

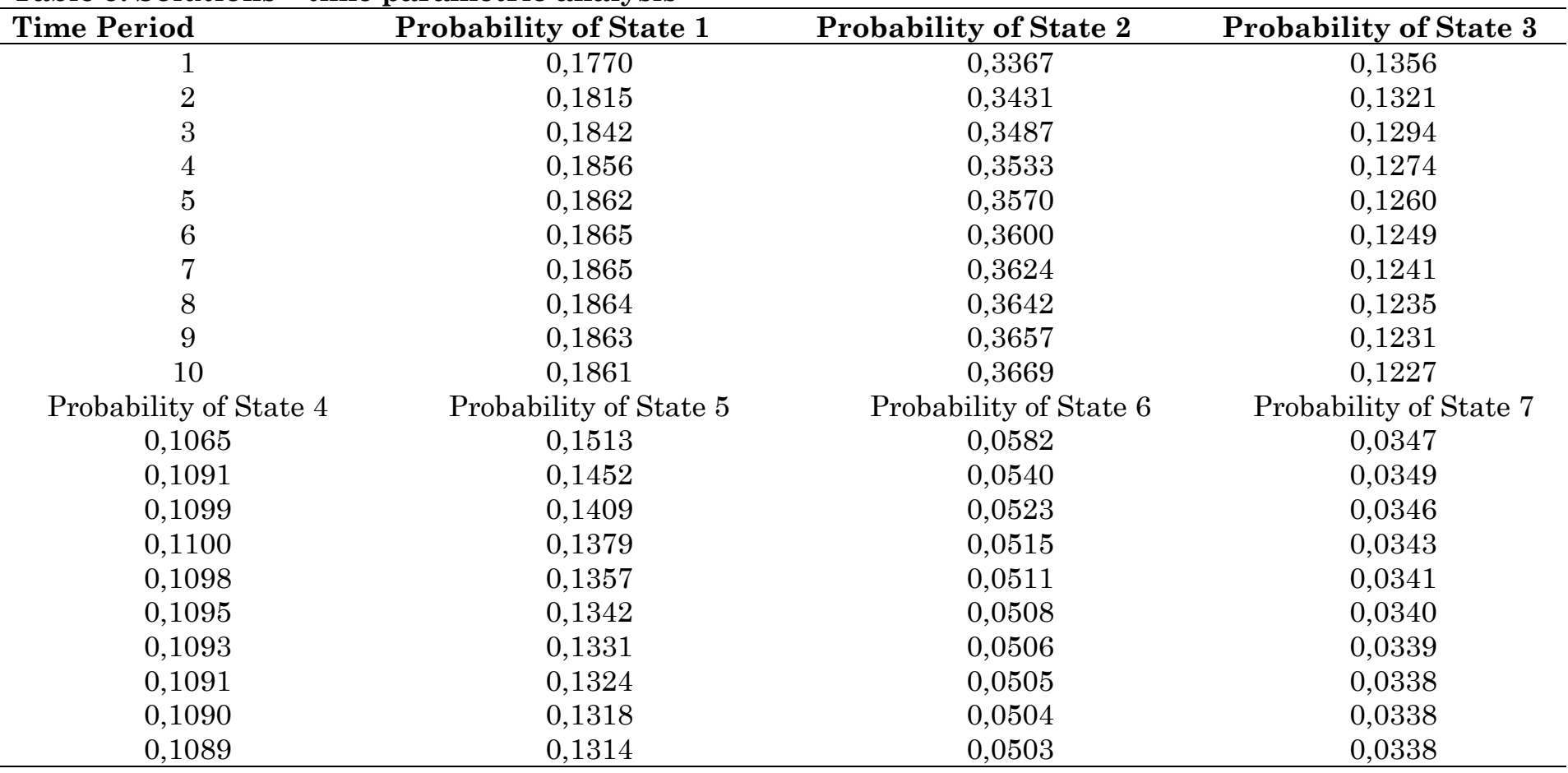

\section{Conclusions}

In this case the Markov chain model has helped to determine the position on the market of furniture products marketed by Logy Bick Company, as well as the estimate of future evolutions according to their main competitors on the market.To carry out this analysis the data were provided by the market study conducted by Ellipse Marketing Company in the points of product sales.So, the right policy to be embedded in Logy Bick strategy could be the increase investments for the expansion of the premium furniture segment. 


\section{Watket shates}

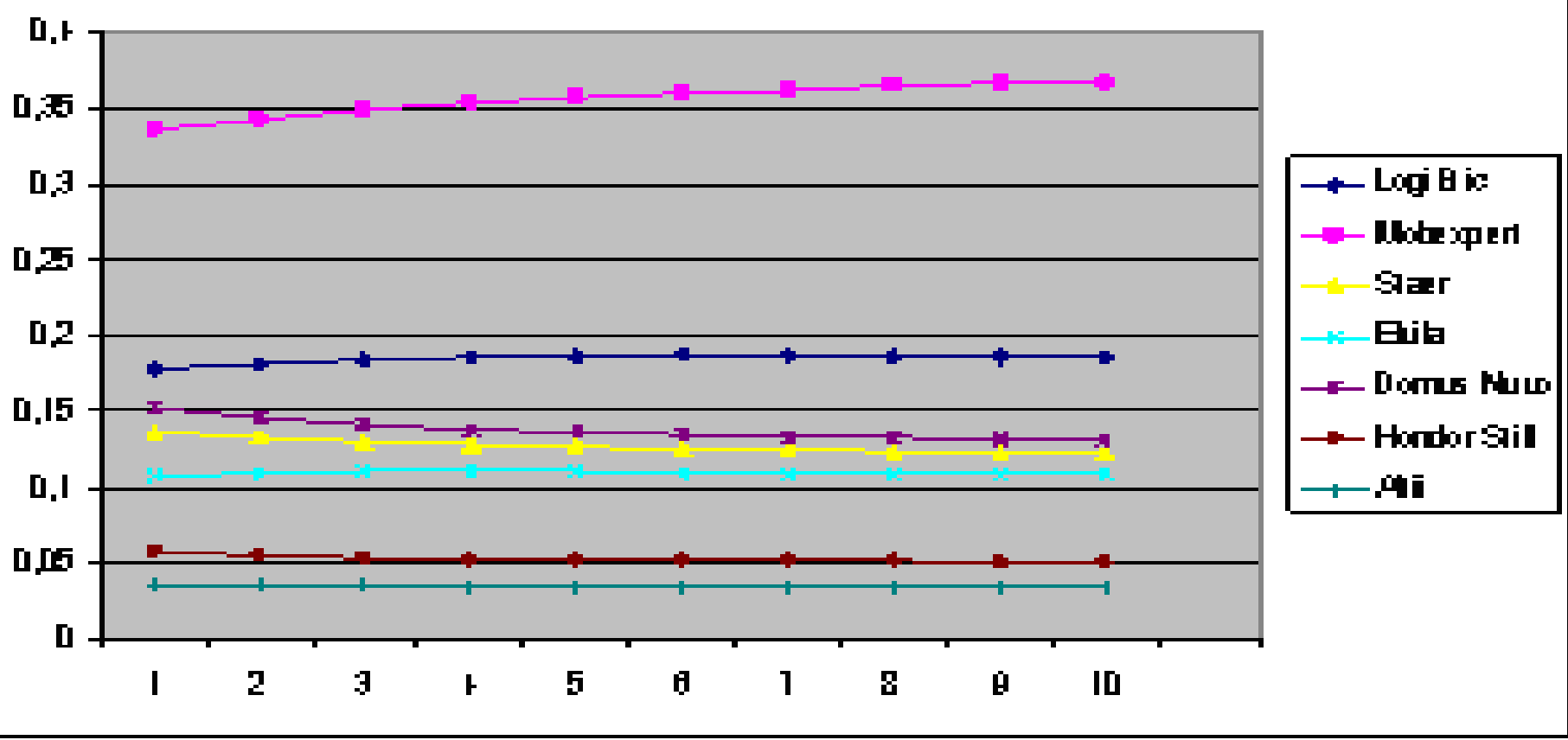

Fig. 2: Evolution of market shares

According to the schedule realized on the basis of the data processed with the help of Markov module (table 5, fig. 2), Logy Bick products presents an ascending trend of the market share.

In this situation the company can substantiate a development strategy through a better knowledge of products by consumers, emphasis actions to promote, which involves an aggressive marketing strategy.

\section{References}

1. Ciobanu E (2009) Ways to grow the economic efficiency of investments, on the processing and use of forest products and accessories. Academy of Economic Studies. Bucharest (PhD Thesis).

2. Gurãu MA (2012) Some contributions in the field of economic evaluation of industrial projects. Polytechnic University. Bucharest (report of $\mathrm{PhD}$ thesis).

3. Negrea R (2010) Stochastic and statistics modeling. Polytechnic University of Timisoara.

4. Oprean C, Tițu M, Bucur V (2011) Overall management of the organizations. Agir Publishing House.

5. Dima CI, Josef N, Duicã C, Cucui FA (2011) Applying the "markov chain" theory in the case of operating several tools. Recent Researches in Social Science, Digital Convergence, Manufacturing and Tourism. http://www.wseas.us/elibrary/conferences/2011/Lanzarote/SOSOMACTS/S OSOMACTS-23.pdf.

\section{Acknowlegdements}

This work is supported by the Sectorial Operational Program for Human Resources Development (SOP HRD), financed from the European Social Fund and by the Romanian Government under the contract number POSDRU/1071.5/S/76909.

6. Rob R, Iordan A, Panoiu C, Panoiu M (2009) Applications of the Markov Stochastic Processes in Functioning of the Energy Entities Modelling. Proceedings of the 13th WSEAS International Conference on SYSTEMS. http://www.wseas.us/elibrary/conferences/2009/rodos/SYSTEMS/SYSTEM S33.pdf.

7. Gurãu MA, Melnic LV (2012) Analysis of the critical path within a project with WinQSB software. Mathematical Models \& Methods in Applied Sciences - Proceedings of the 13th WSEAS International Conference on Mathematics and Computers in Business and Economics p.131-5, http://www.wseas.us/elibrary/conferences/2012/Iasi/ BUBICHE/BUBICHE-16.pdf.

8. Moraru GM (2008) Creativity in Knowledge Based Organizations. Proceedings of the International Conference on Manufacturing Systems ICMaS, 4(2):30-6. 